\title{
BIOACETILAÇÃO DE ÁLCOOIS CATALISADA POR Saccharum officinarum
}

\author{
João Carlos C. Assunção, Telma Leda G. Lemos e Francisco José Q. Monte” \\ Departamento de Química Orgânica e Inorgânica, Universidade Federal do Ceará, CP 1200, 60720-460 Fortaleza - CE, Brasil
}

Recebido em 26/8/08; aceito em 11/2/09; publicado na web em 3/7/09

\begin{abstract}
BIOACETYLATION OF ALCOHOLS CATALYSED BY Saccharum officinarum. Lipase-catalysed esterifications of alcohols using immobilized enzyme system from sugar cane (Saccharum officinarum) as biocatalyst afforded the corresponding esters in considerable yields (68-93\%). Under optimized conditions, the material was utilized for reactions of acetylation with several advantage. It also investigated the possibility of reuse of immobilized enzymes of $S$. officinarum as biocatalyst under optimal reaction conditions.
\end{abstract}

Keywords: biocatalysis; esterifications; Saccharum officinarum.

\section{INTRODUÇÃO}

O uso de plantas como fonte de catalisadores naturais constitui um importante e antigo meio empregado em síntese orgânica, sobretudo, na obtenção de moléculas de interesse biológico, tais como drogas, ${ }^{1}$ cosméticos $^{2}$ e produtos agrícolas. ${ }^{3}$ Nos últimos 10 anos, várias indústrias de química fina exploraram o uso de processos biocatalíticos em síntese orgânica e, em vista da necessidade da elaboração de determinadas substâncias, especificamente, com fins farmacêuticos, um grande número de enzimas foi investigado. ${ }^{3,4}$ As enzimas, embora sejam catalisadores extremamente eficientes, são espécies sensíveis à inativação causada por vários fatores, tais como, temperatura, solvente e pH. Logo, um mecanismo de proteção é essencial para que seu potencial catalítico se mantenha. Diversas técnicas de imobilização de enzimas foram desenvolvidas com a finalidade de fornecer estabilidade, facilitar a recuperação e possibilitar a reutilização desses catalisadores. ${ }^{5}$ A aplicação de enzimas ou complexos enzimáticos imobilizados ${ }^{6}$ cresceu bastante nos últimos anos com a utilização pelas indústrias de medicamentos, detergentes, couros e panificação em seus processos. ${ }^{7,8} \mathrm{O}$ presente trabalho pesquisou o uso do caldo da cana-de-açúcar [Saccharum officinarum, (Poaceae)], planta facilmente cultivável e abundante no Brasil, ${ }^{9,10}$ como fonte de enzimas (sistema imobilizado) para biotransformações em reações de esterificação.

\section{RESULTADOS E DISCUSSÃO}

Os experimentos iniciais consistiram na determinação do total de proteínas $(1,4 \%)$ no sistema enzimático do caldo de cana (CC) empregando o método de Hartree ${ }^{11}$ e, na imobilização do complexo enzimático em um suporte polimérico (alginato de sódio) utilizando o método de Kalogers, ${ }^{12}$ resultando em um percentual de 99,2\% de enzimas imobilizadas do caldo de cana (EICC). As reações de biotransformações começaram por investigar a capacidade redutora das EICC tendo o benzaldeído como substrato. Diferentemente do $\mathrm{CC}$ bruto, ${ }^{13}$ não houve indício de reação, provavelmente, devido à ausência dos cofatores (perdidos no processo de imobilização) que as redutases necessitam para sua atuação. Entretanto, EICC frente ao álcool anísico em mistura com anidrido acético originou um produto identificado através de cromatógrafo gasoso acoplado a espectrômetro de massas (CG-EM) como o acetato do álcool anísico, mostrando a ação biocatalisadora do complexo enzimático

*e-mail: fmonte@dqoi.ufc.br imobilizado. As lipases, enzimas que catalisam este tipo de reação, não necessitam de cofatores. ${ }^{14} \mathrm{O}$ álcool anísico (1) (Figura 1) foi, então, o substrato selecionado para otimização das condições das reações de acetilação de uma série de compostos, utilizando EICC como biocatalisador. Assim, o álcool anísico foi acetilado através de reação usual (anidrido acético/piridina) originando o acetato de anisila (1a) com $95,0 \%$ de rendimento (calculado por CG-EM). O produto 1a foi caracterizado através dos dados dos espectros de massa (EM) e ressonância magnética nuclear de hidrogênio e carbono-13 $\left(\mathrm{RMN}{ }^{1} \mathrm{H}\right.$ $\mathrm{e}^{13} \mathrm{C}$ ). A seguir, o potencial biocatalítico de EICC foi avaliado frente à reação de acetilação do mesmo álcool, a temperatura de $30{ }^{\circ} \mathrm{C}$ e tempo de reação de 72 h e 1 a foi obtido com rendimento de $67,8 \%$. A reação foi, então, realizada em diferentes condições, variando-se os seguintes parâmetros: quantidades de enzima e de substrato, solvente, velocidade de agitação, tempo e temperatura de reação. Após diversas reações, executadas em diferentes situações, ao variar as concentrações do álcool anísico e de EICC na faixa de 50 a $400 \mathrm{mg}$, foi encontrada a relação ideal substrato/enzima, como sendo de 200 $\mathrm{mg} / 150 \mathrm{mg}$. A partir desta relação, foi possível fixar todas as outras condições para a reação de acetilação do álcool catalisada por EICC, de forma a obter um excelente rendimento. Assim, foi efetuado estudo cinético, conforme gráfico da Figura 2. Mantendo a temperatura em $70{ }^{\circ} \mathrm{C}$ e utilizando $150 \mathrm{mg}$ de EICC, $200 \mathrm{mg}$ (1,45 mol) de substrato, $148 \mathrm{mg}(1,45 \mathrm{mmol})$ de anidrido acético, $20 \mathrm{~mL}$ de solvente (hexano) e $150 \mathrm{rpm}$ o acetato de anisila (1a) foi obtido com um rendimento 93,3\% (determinado por CG-EM) após 24 h de reação.

$\mathrm{O}$ espectro de massa de 1a, além do pico do íon molecular em $\mathrm{m} / \mathrm{z} .180$, exibiu picos em $\mathrm{m} / \mathrm{z} 138$ (34\%), 121 (100\%) e 43 (72\%), em acordo com sua estrutura.

Com base nos resultados acima, foi processada a reação de acetilação empregando outros substratos, de modo a comprovar e, possivelmente, ampliar o potencial catalítico de EICC.

Assim, os álcoois benzílico (2), 3-metóxi-benzílico (3), cinâmico (4) e furfurílico (5), de natureza aromática, foram submetidos à acetilação enzimática (Figura 1).

Nesse estudo, foram fixadas as condições otimizadas na bioacetilação do álcool anísico, ou seja, $200 \mathrm{mg}$ do substrato, $150 \mathrm{mg}$ de EICC, $148 \mathrm{mg}$ de anidrido acético, $150 \mathrm{rpm}$, exceto os parâmetros tempo/temperatura, cujos valores foram de $30{ }^{\circ} \mathrm{C} / 72 \mathrm{~h}$ e $70{ }^{\circ} \mathrm{C} / 24 \mathrm{~h}$. Os produtos reacionais foram analisados e tiveram seus rendimentos calculados por RMN ${ }^{1} \mathrm{H}$ e CG-EM (Tabela 1). De modo geral, as reações forneceram produtos que dispensaram purificação, com as amostras tiradas diretamente das soluções reacionais originando espectros que permitiram fáceis interpretações. 


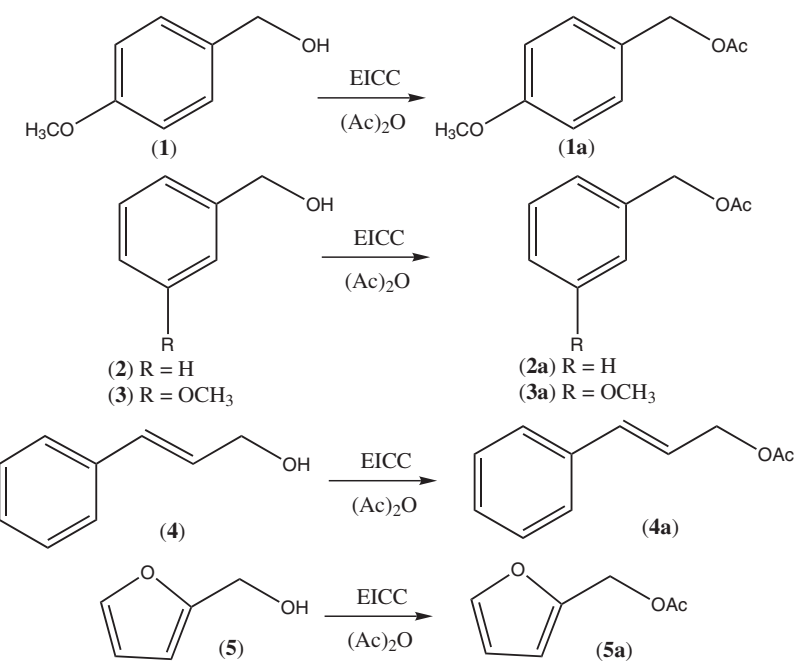

Figura 1. Reação de acetilação enzimática dos alcoóis 1, 2, 3, 4 e 5

Tabela 1. Rendimentos das reações de bioacetilação dos álcoois primários 2-5

RMN ${ }^{1} \mathrm{H}(\%) \quad$ CG-EM $(\%)$

\begin{tabular}{lcccc} 
álcool & $30{ }^{\circ} \mathrm{C}(72 \mathrm{~h})$ & $70{ }^{\circ} \mathrm{C}(24 \mathrm{~h})$ & $30{ }^{\circ} \mathrm{C}(72 \mathrm{~h})$ & $70{ }^{\circ} \mathrm{C}(24 \mathrm{~h})$ \\
\hline $\mathbf{2}$ & 35,0 & 80,2 & 42,3 & 77,7 \\
$\mathbf{3}$ & 26,8 & 68,3 & 46,2 & 68,9 \\
$\mathbf{4}$ & 36,6 & 74,2 & 41,4 & 71,6 \\
$\mathbf{5}$ & 39,0 & - & 49,7 & - \\
\hline
\end{tabular}

Os rendimentos obtidos por $\mathrm{RMN}{ }^{1} \mathrm{H}$ foram determinados através da comparação da integração dos sinais referentes aos hidrogênios carbinólicos dos álcoois com os correspondentes hidrogênios dos acetatos. Os resultados da Tabela 2 demonstraram, claramente, a evolução das reações, através da comparação dos espectros de RMN ${ }^{1} \mathrm{H}$ nas duas temperaturas. Por exemplo, ao final da reação a $30^{\circ} \mathrm{C}, \mathrm{o}$ espectro registrou a presença da mistura binária de $\mathbf{2}$ e $\mathbf{2 a}$, porém, a integração da área do sinal em $\delta_{\mathrm{H}} 4,69$ dos hidrogênios carbinólicos tem quase o dobro da integração do sinal em $\delta_{\mathrm{H}} 5,12$ dos correspondentes hidrogênios do acetato. Por outro lado, na reação a $70{ }^{\circ} \mathrm{C}$, o sinal em $\delta_{\mathrm{H}} 4,71$ dos hidrogênios carbinólicos tem, aproximadamente, apenas $1 / 4$ da integração do sinal em $\delta_{\mathrm{H}} 5,14$, dos correspondentes hidrogênios do acetato, em acordo com o maior rendimento do acetato na reação a $70{ }^{\circ} \mathrm{C}$ e conforme expresso na Tabela 1 . Em adição, o sinal simples em $\delta_{\mathrm{H}} 2,10$ dos hidrogênios do grupo metila no espectro do acetato obtido na reação a $70^{\circ} \mathrm{C}$ tem área maior que o mesmo sinal no acetato obtido a $30^{\circ} \mathrm{C}$. A acetilação foi corroborada também pela comparação

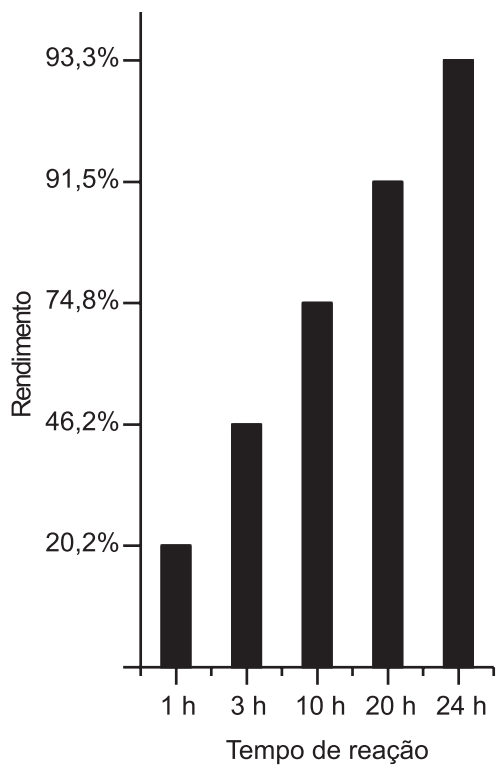

Figura 2. Estudo cinético da reação de acetilação do álcool anísico catalisada por EICC à $70^{\circ} \mathrm{C}$

dos espectros de massa do álcool e do acetato, onde foram observados picos correspondentes aos íons moleculares em $\mathrm{m} / \mathrm{z} .108$ e 150, respectivamente. No espectro de massa do acetato, os principais picos em $m / z, 108,91$ e 43, ratificaram a estrutura do acetato de benzila (2a).

Praticamente, as mesmas observações e conclusões em relação aos espectros de $\mathrm{RMN}{ }^{1} \mathrm{H}$ e de massa puderam ser feitas para os produtos das reações efetuadas com os substratos 3, $\mathbf{4}$ e 5. A reação com o álcool furfurílico (5) foi efetuada somente na temperatura de $30{ }^{\circ} \mathrm{C}$, entretanto, nesta condição, foi observado comportamento semelhante ao dos alcoóis $\mathbf{2 , 3}$ e 4, conforme a Tabela 1 , com rendimento de 49,7\% (CG-EM).

Para efeito de controle, os álcoois anísico e benzílico foram submetidos à reação com anidrido acético em hexano destilado sob dessecante apropriado e atmosfera de nitrogênio, nas temperaturas de 30 e $70{ }^{\circ} \mathrm{C}$. Nos dois casos, produtos de acetilação com rendimentos de somente $4 \%,{ }^{15}$ detectados por CG-EM.

Uma das grandes vantagens da utilização de enzimas imobilizadas em reações de biocatálise é a possibilidade de reutilização, ${ }^{16}$ agregando ao processo um maior valor econômico. Objetivando avaliar o potencial de reuso de EICC, a reação de acetilação do álcool anísico foi repetida cinco vezes consecutivas na temperatura de $30{ }^{\circ} \mathrm{C}$, utilizando as condições otimizadas e um intervalo entre uma reação e outra de $2 \mathrm{~h}$. Os resultados (Figura 3) permitiram concluir que o rendimento de conversão nas reações variou muito pouco $(2,0 \%)$ entre a primeira e a última reação.

Tabela 2. Sinais de hidrogênios selecionados que demonstram através dos deslocamentos químicos e das integrações a conversão dos álcoois (2-5) nos respectivos acetatos (2a-5a) em função da temperatura

\begin{tabular}{|c|c|c|c|c|c|c|c|}
\hline substrato & Temp. $\left({ }^{\circ} \mathrm{C}\right)$ & H-observado & $\delta_{\mathrm{H}}$ & integração & produto & $\delta_{\mathrm{H}}$ & integração \\
\hline \multirow{2}{*}{2} & 30 & $2 \mathrm{H}-1$ & 4,69 (s) & 3,00 & \multirow{2}{*}{$\mathbf{2 a}$} & $5,12(\mathrm{~s})$ & 1,53 \\
\hline & 70 & $2 \mathrm{H}-1$ & $4,71(\mathrm{~s})$ & 0,48 & & $5,14(\mathrm{~s})$ & 1,96 \\
\hline \multirow{2}{*}{3} & 30 & $2 \mathrm{H}-1$ & $4,65(\mathrm{~s})$ & 1,32 & \multirow{2}{*}{$3 \mathbf{a}$} & $5,00(\mathrm{~s})$ & 0,48 \\
\hline & 70 & $2 \mathrm{H}-1$ & $4,65(\mathrm{~s})$ & 1,06 & & $5,08(\mathrm{~s})$ & 2,25 \\
\hline \multirow{2}{*}{4} & 30 & $2 \mathrm{H}-1$ & $4,32(d)$ & 3,00 & \multirow{2}{*}{$4 a$} & $4,74(\mathrm{dd})$ & 1,72 \\
\hline & 70 & $2 \mathrm{H}-1$ & $4,36(d)$ & 0,54 & & $4,80(d)$ & 1,55 \\
\hline 5 & 30 & $2 \mathrm{H}-1$ & $4,59(\mathrm{~s})$ & 1,29 & $5 a$ & $5,02(\mathrm{~d})$ & 1,28 \\
\hline
\end{tabular}




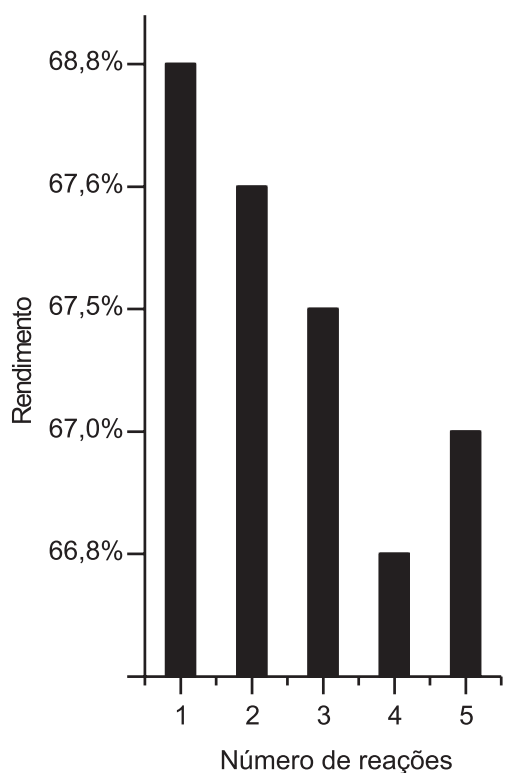

Figura 3. Rendimentos reacionais da acetilação do álcool anísico com EICC após cinco reações com o mesmo material enzimático a $30{ }^{\circ} \mathrm{C}$

Foi testada também a reutilização de EICC a $70{ }^{\circ} \mathrm{C}$ (temperatura que apresentou maior conversão) e, os resultados (Figura 4) permitiram concluir que após a terceira reação o rendimento sofreu um decréscimo relativamente considerável $(7,5 \%)$ em relação à primeira reação.

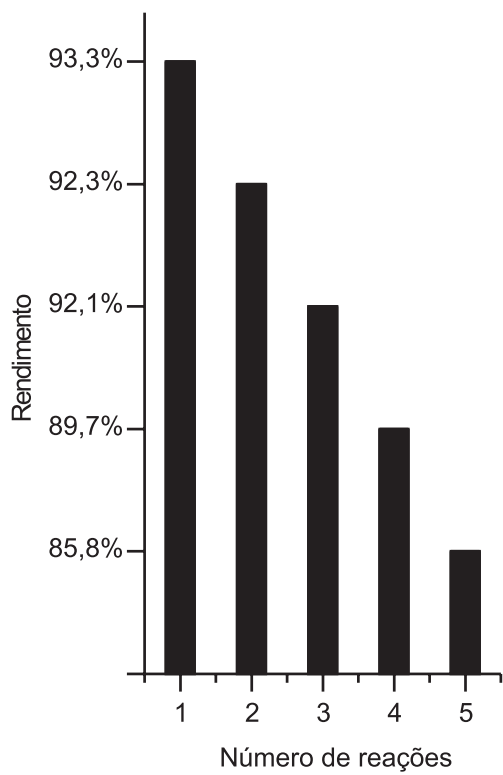

Figura 4. Rendimentos reacionais da acetilação do álcool anísico com EICC após cinco reações com o mesmo material enzimático a $70{ }^{\circ} \mathrm{C}$

\section{PARTE EXPERIMENTAL}

\section{Procedimentos gerais}

Os compostos de partida e os produtos obtidos foram analisados através de cromatógrafo a gás acoplado a espectrômetro de massa (CG-EM) Shimadzu, modelo QP5050A, com injetor tipo split, coluna capilar OV-5 (5\%-pheny)-dimethypolysiloxane (30 m x 0,25 mm x $0,25 \mu \mathrm{m})$; fluxo de $1 \mathrm{~mL} / \mathrm{min}$ para o hélio como gás de arraste. As tem- peraturas do injetor e do detector foram 250 e $280^{\circ} \mathrm{C}$, respectivamente, e a temperatura da coluna foi programada em $4{ }^{\circ} \mathrm{C} / \mathrm{min}$ a partir de 40 até $180^{\circ} \mathrm{C}$ e, então, em $20^{\circ} \mathrm{C} / \mathrm{min}$ de 180 até $280{ }^{\circ} \mathrm{C}$. Os espectros de RMN ${ }^{1} \mathrm{H}(300$ e $500 \mathrm{MHz})$ e de ${ }^{13} \mathrm{C}(75$ e $125 \mathrm{MHz}$ ) foram obtidos em espectrômetros Bruker, modelos Avance DPX 300 e DRX 500, respectivamente, usando $\mathrm{CDCl}_{3}$ como solvente. Os deslocamentos químicos foram dados na escala $\delta$, tendo como referência o sinal do hidrogênio residual do $\mathrm{CDCl}_{3}$ não deuterado.

Os alcoóis 1-5 foram adquiridos da Aldrich Chemical Co, os solventes P.A da Synth e a matriz polimérica (alginato de sódio) para imobilização de enzimas, da Vetec. Nas reações foi empregada uma mesa de agitação magnética modelo CT-165 da Cientec (todas as reações foram processadas a $150 \mathrm{rpm}$ ). Nas cromatografias de adsorção em camada delgada (CCD) foi utilizado gel de sílica 60 ( $\Phi=$ 0,004-0,005 mm) código 1094 da marca Vetec e cromatoplacas de gel de sílica $60(\Phi=2-25 \mu \mathrm{m})$ sobre poliéster T-6145 da Sigma Chemical Co. A revelação das substâncias nas cromatoplacas foi realizada através de pulverização com solução de vanilina $\left(\mathrm{C}_{8} \mathrm{H}_{8} \mathrm{O}_{3}\right)$ e ácido perclórico $0,75 \mathrm{M}\left(\mathrm{HClO}_{4}\right)$ em etanol $\left(\mathrm{C}_{2} \mathrm{H}_{6} \mathrm{O}\right)$, seguida de aquecimento em estufa a $100{ }^{\circ} \mathrm{C}$ por cerca de $3 \mathrm{~min}$. Gel de sílica 60 (70-230 mesh, Vetec) foi usado para cromatografia em coluna.

\section{Material vegetal}

O caldo de cana (CC) de $S$. officinarum foi utilizado ainda em estado fresco.

Imobilização das enzimas

No processo de imobilização das enzimas do caldo de cana foi adotado o procedimento adaptado da metodologia de Kalogeris. ${ }^{12}$ A mistura de $300,0 \mathrm{~mL}$ do caldo em 3,0 g de alginato de sódio foi mantida sob agitação magnética à temperatura ambiente por $2 \mathrm{~h}$, quando foi observada completa miscibilidade dos materiais. Em seguida, a solução de alginato de sódio em caldo de cana foi gotejada através de uma seringa sobre $400,0 \mathrm{~mL}$ de uma solução de $\mathrm{CaCl}_{2} 5 \%$. Findo o gotejamento, a mistura foi deixada em repouso a temperatura ambiente por $20 \mathrm{~h}$. Após este tempo, a solução contendo as enzimas imobilizadas do caldo de cana (EICC) na forma de esferas foi filtrada. As esferas foram lavadas com água destilada e secas à temperatura ambiente, por dois dias, fornecendo um total de 4,0 g. As EICC foram fotografadas por microscopia de varredura eletrônica (MEV) que permitiu a análise de sua morfologia e a determinação do diâmetro de suas partículas, estimado em $0,73 \mathrm{~mm}$.

\section{Procedimentos reacionais}

\section{Acetilação usual de 1}

O composto 1 ( $200 \mathrm{mg}$ ) foi dissolvido em anidrido acético/piridina (4,0:2,0 mL) e a suspensão mantida sob agitação magnética por 24 $\mathrm{h}$ à temperatura ambiente. Após adição de $\mathrm{CuSO}_{4} 5 \%$ e extração com $\operatorname{AcOEt}(2 \times 12 \mathrm{~mL})$, a fase orgânica foi lavada com água, tratada com $\mathrm{Na}_{2} \mathrm{SO}_{4}$ anidro e concentrada sob pressão reduzida. O produto $\mathbf{1 a}$ foi purificado em coluna cromatográfica eluída com $\mathrm{CHCl}_{3}$.

Procedimento geral para bioacetilação dos álcoois

A uma suspensão do composto 1 (200 mg; 1,45 mmol) em 20 $\mathrm{mL}$ de hexano foram adicionados $\mathrm{Ac}_{2} \mathrm{O}$ (148 mg; 1,45 mmol) e EICC $\left(150 \mathrm{mg}\right.$ ). A mistura foi mantida sob agitação magnética a $30{ }^{\circ} \mathrm{C}$, por $72 \mathrm{~h}$. Em seguida, a solução foi concentrada à pressão reduzida, originando 1a (67,8\%). Em experimento à parte, 1a $(95,0 \%)$ foi obtido a partir de $\mathbf{1}$ utilizando as mesmas quantidades do substrato e dos reagentes, porém, na temperatura de $70{ }^{\circ} \mathrm{C}$ e tempo de $24 \mathrm{~h}$. Este procedimento geral foi seguido para os compostos 2-5 na obtenção 
dos produtos 2a-5a.

Acetato de anisila (1a). $\mathrm{RMN}{ }^{1} \mathrm{H}\left(500 \mathrm{MHz}, \mathrm{CDCl}_{3}\right): \delta 7,33(\mathrm{~d}$, $2 \mathrm{H}, J=8,5 \mathrm{~Hz}$ ); 6,91 (d, 2H, $J=8,5 \mathrm{~Hz}) ; 5,09$ (s, 2H), 3,83 (s, 3H); $2,10(\mathrm{~s}, 3 \mathrm{H}) . \mathrm{RMN}{ }^{13} \mathrm{C}\left(75 \mathrm{MHz}, \mathrm{CDCl}_{3}\right): \delta 170,85(\mathrm{C}) ; 159,70(\mathrm{C})$; 130,11 (CH); 129,39 (C); 113,98 (CH); 66,20 ( $\left.\mathrm{CH}_{2}\right) ; 55,21\left(\mathrm{CH}_{3}\right)$; 20,29 $\left(\mathrm{CH}_{3}\right)$. EMEI (70 eV): $m / z, 180\left(\mathrm{M}^{+}\right) ; 138$ (34); 121 (100); $43(72)$.

Acetato de benzila (2a). $\mathrm{RMN}{ }^{1} \mathrm{H}\left(500 \mathrm{MHz}, \mathrm{CDCl}_{3}\right): \delta 7,42$ (sl); 5,14 (s); 2,11 (s). EMEI (70 eV): $m / z, 150\left(\mathrm{M}^{+\bullet}\right) ; 108$ (100); 91 (80); 43 (62).

Acetato de 3-metóxi-benzila (3a). $\mathrm{RMN}{ }^{1} \mathrm{H}\left(500 \mathrm{MHz}, \mathrm{CDCl}_{3}\right)$ : $\delta$ 7,28 (m); 6,90 (m); 5,08 (s); 3,80 (s); 2,11 (s). EMEI (70 eV): m/z $180\left(\mathrm{M}^{+}\right.$); 138 (100); 121 (33); 109 (35); 91 (37); 43 (43).

Acetato de cinamila $(4 a)$. $\mathrm{RMN}{ }^{1} \mathrm{H}\left(300 \mathrm{MHz}, \mathrm{CDCl}_{3}\right): \delta 7,35$ (m); 6,76 (d, $J=15,9 \mathrm{~Hz}) ; 6,36(\mathrm{~m}) ; 4,37$ (d, $J=6,3 \mathrm{~Hz}) ; 2,10$ (s). EMEI (70 eV): m/z $176\left(\mathrm{M}^{+} ; 22\right) ; 134$ (39); 115 (75); 105 (38); 92 (30); 43 (100).

Acetato de furfurila (5a). RMN ${ }^{1} \mathrm{H}\left(500 \mathrm{MHz}, \mathrm{CDCl}_{3}\right): \delta 7,35$ (s); 6,40 (s); 3,29 (s). EMEI (70 eV): $\mathrm{m} / \mathrm{z} 140\left(\mathrm{M}^{+*} ; 53\right) ; 98$ (87); 81 (100); 43 (66).

\section{CONCLUSÃO}

Em síntese, foi demonstrado que o sistema enzimático (EICC) do suco fresco da cana-de-açúcar ( $S$. officinarum) em sua forma imobilizada exerceu, efetivamente, função como catalisador em reações de acetilação, tendo como substratos álcoois de baixo peso molecular, produzindo acetatos com bons a elevados rendimentos (68-93\%). Em adição, a repetição da reação na temperatura de 30 ${ }^{0} \mathrm{C}$ usando o álcool anísico como substrato mostrou que o sistema enzimático, na forma imobilizada, pode ser reutilizado em até cinco vezes consecutivas sem diminuição considerável de rendimento. Esses dados, certamente, servem como incentivo ao estudo de diversos outros vegetais comuns e abundantes de nossa flora, possibilitando a realização de reações levando em consideração aspectos relevantes não somente do ponto de vista econômico, como também, evitando, em muitos casos, reagentes caros, tóxicos, explosivos e prejudiciais ao meio ambiente.

Os resultados mostraram que é possível esperar rendimentos ainda maiores em função da variação de outros parâmetros reacionais como, por exemplo, a matriz polimérica de imobilização do sistema enzimático e o doador de grupo acila exigindo, assim, a realização de novos experimentos.

Os rendimentos dos produtos obtidos nas reações de controle foram apenas de $4 \%$, ao passo que os rendimentos dos produtos obtidos com EICC, na faixa de $68-93 \%$, foram importantes do ponto de vista prático.

\section{AGRADECIMENTOS}

Ao CNPq e à CAPES pelas bolsas e auxílios concedidos.

\section{REFERÊNCIAS}

1. Luna, H.; Rev. Soc. Quim. Mex. 2004, 48, 211.

2. Veit, T.; Eng. Life Sci. 2004, 4, 508.

3. Liu, Z.; Weis, R.; Gleider, A.; Food Technol. Biotechnol. 2004, 42, 237.

4. Thayer, A. M.; Chem. Eng. News 2006, 14, 15.

5. Villeneuv, P.; Muderhwa, J. M.; Graille, J.; Hoss, M. J.; J. Mol. Catal. B: Enzym. 2000, 9, 113.

6. Cordell, G. A.; Lemos, T. L. G.; Monte, F. J. Q.; Mattos, M. C.; J. Nat. Prod. 2007, 70, 478.

7. Pandey, A.; Benjamin, S.; Soccol, C. R.; Nigan, P.; Krieger, N.; Soccol, V. T.; Biotechnol. Appl. Biochem. 1999, 29, 119.

8. Salunkhe,, M. M.; Nair, R.; J. Mol. Catal. B: Enzym. 2000, 10, 535.

9. Magalhães, P. S. G.; Cerri, D. G. P.; Bios. Eng. 2007, 1, 96.

10. http://www.agricultura.gov.br, acessada em Março 2007.

11. Hartree, E. F.; Ana. Biochem. 1972, 48, 422.

12. Kalogers, E.; Sanakis, Y.; Mamma, D.; Christakopoulos, P.; Kekos, D.; Stamatis, H.; Enzyme Microb. Technol. 2006, 39, 1113.

13. Assunção, J. C. C.; Machado, L. L.; Lemos, T. L. G.; Cordell, G. A.; Monte, F. J. Q.; J. Mol. Catal. B: Enzym. 2008, 52, 194.

14. Dalla-Vecchia, R.; Nascimento, M. G.; Soldi, V.; Quim. Nova 2004, 27, 623.

15. Machado, L. L.; Lemos, T. L. G.; Mattos, M. C.; Oliveira, M. C. F.; de Gonzalo, G.; Gotor-Fernandez, V.; Gotor, V.; Tetrahedron: Asymmetry 2008, 19, 1418 .

16. Soares, C. M.; Castro, H. F.; Moraes, F. F.; Zanin, G. M.; Appl. Biochem. Biotechnol. 1999, 77, 745. 